\title{
LA INVIABILIDAD DEL DERECHO PENAL INTERNACIONAL EN UN MUNDO DE FUERZA CERO. ¿JUSTICIA INTERNACIONAL PARA LOS CRÍMENES DEL ESTADO ISLÁMICO?
}

\author{
THE UNVIABILITY OF INTERNATIONAL CRIMINAL \\ LAW IN A ZERO-STRENGTH WORLD. INTERNATIONAL \\ JUSTICE FOR THE CRIMES OF THE ISLAMIC STATE?
}

\section{LA NON-VIABILITÉ DU DROIT PÉNAL INTERNATIONAL DANS UN MONDE DE FORCE ZÉRO. JUSTICE INTERNATIONALE POUR LES CRIMES DE L'ÉTAT ISLAMIQUE?}

\author{
BorJa García VázQuez \\ Universidad Autónoma de Nuevo León \\ borjagarcia131@gmail.com \\ Raúl Carnevali Rodríguez \\ Universidad de Talca, Chile \\ rcarnevali@utalca.cl
}

RESUMEN: La consolidación del derecho penal internacional ha sido propiciada por contextos geopolíticos de liderazgo de un grupo minoritario de potencias, como ocurrió tras el final de la Segunda Guerra Mundial y de la Guerra Fría. Actualmente, el mundo se encuentra de nuevo en una posición de ausencia de guía por un único Estado, impidiendo con ello el ejercicio del derecho penal internacional, tanto en la forma de los tribunales ad hoc o de tribunales mixtos, como por la incapacidad de operación de la Corte Penal Internacional ante la fragmentación mundial, como lo ha evidenciado la guerra civil siria, conflicto ante el cual puede trazarse un paralelismo histórico con lo sucedido durante la guerra civil española, constatando la inviabilidad del derecho penal internacional en un supuesto de vacío de liderato.

Palabras clave: derecho penal internacional; derecho internacional humanitario; guerra civil siria; crímenes de guerra. 
Aвstract: Consolidation of international criminal law has been fostered by geopolitical contexts of leadership by a minority group of powers, as happened after the end of the Second World War and during the Cold War. Today, the world is once again in a position of lack of guidance by a single State, hindering the exercise of international criminal law, both in the form of $a d$ hoc or mixed courts, as well as the ineffectiveness of the International Criminal Court in the face of global fragmentation. This is evidenced by the Syrian civil war, a conflict which finds historical parallels with the Spanish civil war, confirming the unviability of international criminal law in a situation of a vacuum of leadership.

Keywords: international criminal law; international humanitarian law; Syrian civil war; war crimes.

\section{Traducción de Fionn Petch, cm Idiomas}

RÉSumÉ : La consolidation du droit pénal international a été favorisée par des contextes géopolitiques de leadership d'un groupe minoritaire de pouvoirs, comme cela s'est produit après la fin de la Seconde Guerre mondiale et de la guerre froide. Actuellement, le monde se retrouve à nouveau dans une situation d'absence d'orientation par un seul État, empêchant ainsi l'exercice du droit pénal international, tant sous la forme de tribunaux ad hoc ou de tribunaux mixtes, que du fait de l'incapacité de la Cour pénale internationale de fonctionner face à la fragmentation mondiale, comme en témoigne la guerre civile syrienne, un conflit dans lequel un parallèle historique peut être établi avec ce qui s'est passé pendant la guerre civile espagnole, confirmant la non-viabilité du droit pénal international dans le cas d'un vide de leadership.

Mots-clés: droit pénal international ; droit international humanitaire ; guerre civile syrienne ; crimes de guerre.

Traducción de Rafael Segovia, cm Idiomas

Fecha de recepción: marzo de 2020.

Fecha de aceptación: julio de 2021. 


\section{INTRODUCCIÓN}

A

diferencia de la Guerra Fría, caracterizada por el enfrentamiento entre bloques antagónicos y alternativos, el colapso de la Unión Soviética (URss), en 1991, constituyó para Fukuyama el fin de la historia, traducido en la victoria del modelo económico liberal, cimentado en la democracia y la protección de la libertad de las personas, ${ }^{1}$ del cual Estados Unidos (EE.UU.) ha sido su máximo exponente, como única superpotencia mundial. Ello permitió la generación de consensos en el marco del Consejo de Seguridad de la Organización de las Naciones Unidas (ONU), respecto de la creación de tribunales ad hoc para enjuiciar las violaciones del derecho internacional humanitario y otros crímenes atroces producidos en lo que fuera el territorio de la antigua Yugoslavia y de Ruanda, posición que ostentaría hasta los atentados terroristas del 11 de septiembre de 2001, cometidos en su territorio continental por la organización Al-Qaeda, que llevaron al país a intervenir militarmente en Afganistán e Iraq.

Con posterioridad a estos atentados, no se han vuelto a constituir tribunales ad hoc para enjuiciar crímenes contrarios al derecho internacional humanitario, pero sí han operado tribunales mixtos, según el acuerdo de la onu y el gobierno del Estado que haya padecido estos hechos, bajo supuestos destinados a evitar la impunidad de los crímenes soportados por "incapacidad gubernamental o presiones políticas". ${ }^{2}$ En este contexto, la invasión estadounidense de Iraq, un acto de ocupación militar, descrita en palabras de Diez de Velasco Vallejo como "el ejercicio de una autoridad meramente transitoria o provisional sobre el territorio ocupado-que se ha de resolver finalmente por medio de la restitución del territorio

${ }^{1}$ Francis Fukuyama, ¿El fin de la Historia? y otros ensayos, Madrid, Alianza Editorial, 2019, p. 61.

${ }^{2}$ Alfredo Liñán Lafuente, "Los tribunales penales híbridos e internacionalizados", en Alicia Gil y Elena Maculan, Derecho penal internacional, Madrid, Dykinson, 2019, p. 115. 
o de otras soluciones que ofrece el derecho internacional-, de tal forma que la situación jurídico-internacional del Estado ocupado permanece inalterada, y en consecuencia el territorio ocupado sigue siendo territorio de dicho Estado", ${ }^{3}$ lo que supuso una ruptura del paradigma internacional al crearse, en 2003, por mandato estadounidense, el tribunal especial de Iraq, institución dependiente de EE.uU. debido a su financiación y funcionamiento, ${ }^{4}$ lo que podría interpretarse como una vulneración de la soberanía iraquí.

En la actualidad, EE.UU. ha perdido su posición hegemónica global, sobre todo con el crecimiento diplomático, económico y militar de China. De esta forma, el mundo se encuentra hoy, como lo expresan Bremmer y Roubini, en una situación de ausencia de liderazgo internacional por un único país, ante la escasez de medios políticos y económicos para construir una agenda mundial, lo que lleva a los Estados a una constante competición negativa y generadora de conflictos. ${ }^{5}$ Este hecho ha desestabilizado regiones como el Medio Oriente, permitiendo la aparición de grupos criminales capaces de proyectar su fuerza internacionalmente.

Tal es el caso de DAESH o IsIs, que significan en árabe e inglés, respectivamente, las siglas del Estado Islámico de Iraq y el Levante (EI en adelante), organización terrorista cuyo líder, Abu Bakr al-Baghdadi, proclamó el 26 de junio de 2014 el califato del Estado Islámico, el cual se extendía territorialmente desde el norte de Siria, hasta la frontera con Irán, convirtiéndose en un actor no estatal que contaba con elementos típicos de un Estado, como el ejército (al disponer de 15000 a 35000 combatientes, de los cuales unos 3000 eran europeos

${ }^{3}$ Manuel Diez de Velasco Vallejo, Instituciones de derecho internacional público, Madrid, Tecnos, 2013, p. 442.

${ }^{4}$ Alfredo Liñán Lafuente, op. cit., p. 138.

5 Ian Bremmer y Nouriel Roubini, "A G-Zero World", Foreign Affairs, marzo-abril de 2011, https:/ / www.foreignaffairs.com/articles/2011-01-31/ g-zero-world 
y 100 estadounidenses, ${ }^{6}$ junto a otros miles de extranjeros, que acudieron por motivos ideológicos y pecuniarios, como es el caso de francotiradores chechenos, que recibían mensualmente hasta 7000 dólares $^{7}$ ) e ingresos económicos (de aproximadamente 2000 millones de dólares, con una ganancia diaria de un millón por la venta del petróleo sirio $^{8}$ a Turquía, a un precio de 20 a 50 dólares, gracias a la producción de 80000 a 100000 barriles por día ${ }^{9}$ ).

El 13 de noviembre de 2014, el EI emitió un comunicado oficial anunciando la fundación de enclaves externos de los territorios de Iraq y Siria, situados en Arabia Saudí, Argelia, Egipto, Libia y Yemen, ${ }^{10}$ lo que supuso la ruptura con AlQaeda, ${ }^{11}$ organización de la cual había surgido, pero a diferencia de ésta, que está dirigida a la lucha global, este grupo centró sus medios en el ámbito territorial. ${ }^{12}$

El EI es además exponente del terrorismo de tercera generación o 3G, por su capacidad de utilizar los medios de comunicación con el objetivo de propagar su mensaje más allá del territorio en el que se encuentre, ${ }^{13}$ concordando con el carácter universalista del islam, que ha fijado internet como el medio idóneo para reunir a sus adeptos. ${ }^{14}$ Aunque Al-Qaeda se concibió para funcionar de forma descentralizada, sin requerir ningún tipo de apoyo para sus actividades (hecho que permitió a la organización sobrevivir a la muerte de su líder,

${ }^{6}$ M. Foucher, "Una ambición territorial”, en É. Fottorino, Qué es ISIS: ensayos para comprender el terrorismo actual, Ciudad de México, Ediciones Culturales Paidós, 2016, pp. 45-47.

${ }^{7}$ O. Weber, "El feudo del terror" en É. Fottorino, op. cit., p. 138.

${ }^{8}$ M. Foucher, op. cit., p. 49.

${ }^{9}$ H. Dawod, "El Estado Islámico está muy adaptado a la guerra moderna", en É. Fottorino, op. cit., p. 57.

${ }^{10}$ Carlos Igualada Tolosa, "Dáesh: provincias y grupos afiliados", Ejército, vol. LXxix, núm. 930, 2018, p. 12.

${ }^{11}$ H. Thiollet, "El espectro de la invasión de 2003", en É. Fottorino, op. cit., p. 41.

12 J. P. Filiu, "Un enfrentamiento apocalíptico", en ibid., p. 153.

13 É. Fottorino, "Introducción", en ibid., p. 9.

${ }^{14}$ M. Onfray, "La escoba del aprendiz de brujo", en ibid., p. 67. 
Bin Laden, y a la intervención militar de Afganistán ${ }^{15}$ ), EI se focalizó en luchar en la región de Iraq aprovechando el vacío institucional, y así expandirse hasta tomar gran parte del territorio sirio.

Ante esta coyuntura, la finalidad del presente artículo es exponer la viabilidad del derecho penal internacional ante la fragmentación del orden internacional, y su operatividad frente a la situación de la guerra civil siria, en cuyo teatro de operaciones se han cometido crímenes contra bienes jurídicos protegidos por esta rama de la ciencia del Derecho; un orden jurídico que ha sido impracticable en supuestos de conflicto con participación activa de múltiples Estados y combatientes extranjeros (equiparable a lo ocurrido en la guerra civil española), y cuyo empleo ha sido factible en determinadas circunstancias de unanimidad de los miembros de la comunidad internacional (como en los tribunales para la ex Yugoslavia y Ruanda), o ante posiciones de disparidad de poder, en las que pudo transmitirse una situación de ajusticiamiento de los vencedores a los vencidos (similar a los denominados juicios de Núremberg).

\section{LA GUERRA CIVIL ESPAÑOLA Y LOS COMBATIENTES}

EXTRANJEROS: SUPUESTO HISTÓRICO DE FUERZA CERO

En la primera mitad del siglo xx, España atravesó una crisis de Estado como resultado de los siete años de dictadura del general Miguel Primo de Rivera, 1923-1930. Eso llevó al país a un nuevo régimen político, como consecuencia de las elecciones municipales convocadas por el gobierno presidido por el almirante Aznar, en las que surgieron como vencedores -en las grandes ciudades-, las candidaturas republicanas

15 E. Hobsbawn, Guerra y paz en el siglo XXI, Ciudad de México, Ediciones Culturales Paidós, 2019, p. 171. 
y socialistas, culminando todo ello en la proclamación de la Segunda República el 14 de abril de 1931. ${ }^{16}$

El ensayo democrático español se vio frustrado por numerosos factores, como la inestabilidad entre las distintas fuerzas políticas, que condujeron a la radicalización, el matonismo y el pistolerismo entre los partidos, y acontecimientos que afectaron al conjunto de la ciudadanía, como los sucesos de Casas Viejas en enero de 1933, la insurrección obrera de Asturias, en octubre de 1934, o el asesinato del diputado José Calvo Sotelo, el 13 de julio de 1936, con el colofón de la sublevación del Ejército contra la República, junto con una amalgama de fuerzas que terminarían comandadas por el general Francisco Franco, llevando al país a una guerra civil que lo asoló, hasta la derrota definitiva del bando republicano el 1 de abril de 1939.

Entre los sublevados existió la creencia de que para el 20 de julio de 1936 se había preparado un levantamiento comunista, sin que al día de hoy haya sido demostrada la veracidad de esta información, ${ }^{17}$ y cuya amenaza real residía en el cumplimiento del programa político del Frente Popular contra la oligarquía española de aquel tiempo, formada por terratenientes y financieros, apoyada por una masa rural y legitimada por el Ejército y la Iglesia; ${ }^{18}$ ello dio lugar a un bando uniforme, en el que convergieron militares contrarios al nuevo gobierno, junto a milicianos tradicionalistas (requetés), fascistas (provenientes de Falange) y monárquicos del antiguo régimen (miembros de Acción Popular y de Renovación Española). ${ }^{19}$

Este conflicto se caracterizó por su internacionalización, el componente antifascista y la creación de las Brigadas In-

16 Manuel Tuñón de Lara, La Segunda República, Madrid, Grupo 16, 1985 , p. 4.

${ }^{17}$ José Andrés-Gallego y Antón M. Pazos, Archivo Gomá: documentos de la guerra civil, Madrid, Consejo Superior de Investigaciones Científicas, 2001, p. 81.

18 Julio Aróstegui, La guerra civil, Madrid, Grupo 16, 1985, p. 10.

${ }^{19}$ José Andrés-Gallego y Antón M. Pazos, op. cit., pp. 82-83. 
ternacionales (ві), ${ }^{20}$ que entre el otoño de 1936 y 1939 , permitieron a más de 30000 voluntarios extranjeros comprometidos políticamente (los brigadistas) viajar desde diferentes países a España, con la finalidad de combatir en la guerra, en una acción coordinada desde la uRss por la Internacional Comunista. ${ }^{21}$ Así lo muestran los informes de la época, donde puede verse que los altos grados de dirección de estas tropas estuvieron ocupados por comunistas. ${ }^{22}$

El volumen de voluntarios extranjeros que acudieron a España alcanzó tal número, que para el otoño de 1936 se organizaron brigadas separadas, como la "Thaelman", integrada por alemanes contrarios a Hitler, o la "Garibaldi", formada por italianos anti Mussolini. ${ }^{23} \mathrm{Si}$ bien durante el conflicto las BI tuvieron 60000 extranjeros alistados, al momento de su repatriación oficial no llegaban a los 12000 soldados, de los cuales prácticamente la mitad se quedó en España hasta el final de la guerra. ${ }^{24}$

Durante la contienda, aquellos brigadistas hechos prisioneros tuvieron los siguientes destinos: fueron internados en campos de concentración, como el de San Pedro de Cardeña, en Burgos, donde de 653 prisioneros, 479 habían perte-

20 Ángel Viñas, "La creación de las Brigadas Internacionales", en Josep Sánchez Cervelló y Sebastián Agudo Blanco, Las Brigadas Internacionales: nuevas perspectivas en la historia de la Guerra Civil y del exilio, Tarragona, Publicaciones URv, 2015, p. 15.

${ }^{21}$ Alejandro de Quesada, The Spanish Civil War: 1936-1939 (2) Republican Forces, Gran Bretaña, Osprey Publishing, 2015, p. 16.

22 Ernst Nolte, La guerra civil europea, 1917-1945: nacionalsocialismo y bolchevismo, México, Fondo de Cultura Económica, 2001, p. 259.

${ }^{23}$ Abraham Lincoln Brigade Archives, "Jewish Volunteers in the Spanish Civil War", en Abraham Lincoln Brigade Archives, 21 de noviembre de 2008, http://www.alba-valb.org/resources/lessons/jewish-volunteers-inthe-spanish-civil-war/jewish-volunteers-in-the-spanish-civil-war

${ }^{24}$ Gabriel Cardona, "El Ejército popular y las Brigadas Internacionales. ¿Cuál fue la importancia de las brigadas?”, en Manuel Requena Gallego y Rosa María Sepúlveda Losa, Las brigadas internacionales: el contexto internacional, los medios de propaganda, literatura y memorias, Cuenca, Ediciones de la Universidad de Castilla-La Mancha, 2003, p. 37. 
necido a las BI; o bien fueron fusilados después de consejos de guerra (práctica habitual en el primer año de ésta, aunque no se tienen datos exactos del total de ejecutados) o deportados, para aquellos cuyos países de origen se encontraban bajo el dominio del III Reich. ${ }^{25}$

Los combatientes que pudieron retornar a sus países de procedencia, lo hicieron durante tres periodos: en primer lugar, las repatriaciones individuales ocurridas entre el invierno de 1936 y el verano de 1938; la segunda, la retirada oficial de las BI en otoño de 1938 y, por último, la de los brigadistas internados en los campos del sur de Francia al final de la contienda. ${ }^{26} \mathrm{El}$ destino de los brigadistas internacionales que pudieron abandonar España fue diverso: reprimidos con dureza, en Bélgica, Holanda, Polonia, Suiza o la urss (o en menor medida, como EE.UU. y la Gran Bretaña); vitoreados, en México y Yugoslavia; y ninguneados en el caso de Francia (sin olvidar que muchos de ellos volvieron a sus países heridos o enfermos, y se vieron afectados por el desempleo). ${ }^{27}$

Lo que distingue la aportación de hombres en el bando franquista y el republicano es que mientras en el primero se trataba de personal militar, ya fuese alemán o italiano, del lado republicano no existía unidad en el origen y profesionalización de los combatientes. El bando franquista se benefició de la ayuda brindada por el III Reich de Adolf Hitler, con la Legión Cóndor, formada por unos 5000 voluntarios (nominalmente) que permitieron la superioridad aérea de las fuerzas sublevadas ${ }^{28}$ y de la Italia fascista de Benito Mussolini, con

25 Gerhard Hoffmann, "Prisioneros internacionales en los campos de concentración de Franco", Ebre 38: revista internacional de la guerra civil, 1936-1939, 2017, pp. 12-16.

${ }^{26}$ Rémi Skoutelsky, "El regreso de los voluntarios. La memoria de las Brigadas”, en Manuel Requena Gallego y Rosa María Sepúlveda Losa, Las brigadas internacionales: el contexto internacional, los medios de propaganda, $l i$ teratura y memorias, Cuenca, Ediciones de la Universidad de Castilla-La Mancha, 2003, p. 144.

${ }^{27}$ Manuel Requena Gallego y Rosa María Sepúlveda Losa, "Prólogo”, en Manuel Requena Gallego y Rosa María Sepúlveda Losa, ibid., p. 11.

28 Ernst Nolte, op. cit., p. 261. 
el Cuerpo de Tropas voluntarias, un contingente expedicionario que llegó a estar compuesto por 80000 soldados durante los tres años que duró el enfrentamiento. ${ }^{29}$ La intervención alemana en la guerra se dio, en sus primeras etapas, entre el 15 de noviembre de 1936 y el 20 de marzo de $1937,{ }^{30}$ y ésta fue decisiva (pese a que Italia aportó una mayor cantidad de material $)^{31}$ lo que ocasionó que la deuda de gratitud de España fuese principalmente al país germano. ${ }^{32}$ Por estas razones, el conflicto fue percibido por Alemania, Italia y la uRss como un laboratorio para poner a prueba sus doctrinas en víspera de la Segunda Guerra Mundial (1939-1945), ${ }^{33}$ lo que supone una muestra del grado de internacionalización de la guerra.

Sánchez Asiaín dedica el capítulo xxiII de su obra a "La financiación de la guerra civil española”, donde expone los distintos estudios realizados para tratar de concretar la cifra real de pérdida de vidas humanas durante la contienda de España, criticando la versión tradicional defendida por los vencedores y los vencidos (de un millón de muertos) originada en la carta pastoral "La Cuaresma en España", del cardenal Gomá, de enero de 1937, contraponiendo a estudiosos como Hugh Thomas (de 600000 , incluyendo a aquellos muertos por el hambre) o a Salas Larrazábal (de 625000, que contiene a los fallecidos en la posguerra, como consecuencia de la participación de españoles en la Segunda Guerra Mundial y las acciones del maquis) para finalmente indicar que las con-

${ }^{29}$ Marco Carrubba, "La memoria del Cuerpo de Tropas Voluntarias en las publicaciones del régimen fascista y en las biografías de los voluntarios”, I Encuentro de Jóvenes Investigadores en Historia Contemporánea de la Asociación de Historia Contemporánea: Zaragoza, 26, 27 y 28 de septiembre de $2007,2008$.

${ }^{30}$ Cesáreo Oliver Monteso, "La Legión Cóndor en Navarra - campo de aviación de Buñuel - 1937-1938", Revista del Centro de Estudios Merindad de Tudela, 2010, p. 7.

${ }^{31}$ Laura Ramírez Sainz, "La Legión Cóndor desde varias perspectivas", maGAzin, 2006, p. 44.

${ }^{32}$ Ramón Salas, "La división azul”, Espacio, Tiempo y Forma, 1989, p. 241.

${ }^{33}$ Steven J. Zaloga, Spanish Civil War: the providing ground for Blitzkrieg, Gran Bretaña, Osprey Publishing, 2010, p. 5. 
clusiones alcanzadas por Martín Rubio en 1999 situarían la disminución de población teórica en 1458551 personas, al conjugar los fallecidos de la contienda y los que sufrieron represalias de la posguerra, con el descenso de natalidad y los exiliados que abandonaron España de forma permanente. ${ }^{34}$

Por otra parte, si nos centramos en la cifra de ejecutados en las retaguardias de batalla, a través del estudio de Preston, en el bando republicano se habría procedido al ajusticiamiento de algo más de 47000 personas, mientras que para el mismo periodo, aquellos que sufrieron represalias por el bando franquista entre 1936 y 1939 rondarían los 127500 muertos. $^{35}$ Hasta la desaparición del régimen franquista en noviembre de 1975 , se estima que fueron asesinados entre 75000 y 150000 soldados republicanos y civiles partidarios de la República. ${ }^{36}$

Lo que determinó el escenario internacional durante la contienda española fue el fracaso de la Sociedad de Naciones (organización internacional existente en aquel momento para evitar nuevos estallidos de violencia) junto con la inestabilidad y el disenso entre las principales potencias, encarnadas primordialmente en la incompatibilidad entre el totalitarismo alemán y soviético. No sería hasta el final de la Segunda Guerra Mundial, con la derrota de los fascismos que habían gobernado en buena parte de Europa y Asia, que se estableció la primacía de los Tribunales Militares creados ex profeso, para juzgar los crímenes de guerra, contra la paz y contra la humanidad. ${ }^{37}$

Por el contrario, la posguerra (caracterizada por una situación de oposición internacional, entre EE.UU. y la URss) impidió, debido a intereses geopolíticos, la adopción de medidas

34 José Ángel Sánchez Asiaín, La financiación de la guerra civil española, Barcelona, Crítica, 2012.

35 Paul Preston, El holocausto español, Madrid, Debate, 2011.

36 Mike Elkin, “Opening Franco’s Graves”, Archaeology, 2006.

37 Raúl Carnevali Rodríguez, "Los principios de primacía y complementariedad. Una necesaria conciliación entre las competencias de los órganos penales nacionales y los internacionales", Revista de Derecho de la Universidad Austral de Chile, 2010, p. 185. 
destinadas a ejercitar cualquier mecanismo de justicia contra los crímenes de guerra y otros crímenes atroces cometidos en los múltiples conflictos que se sucedieron, mientras perduró el antagonismo. Sólo a partir de la desmembración soviética volvieron a operar los tribunales internacionales para atender las graves violaciones humanitarias cometidas en Yugoslavia y Ruanda, ante la incapacidad de los tribunales nacionales. ${ }^{38}$

Huntington, apoyando las opiniones de Bernard-Henri Lévy, observa la guerra civil española como ejemplo de enfrentamiento entre sistemas e ideologías políticas, que sirvió de antesala a la Segunda Guerra Mundial, encontrando su equivalente contemporáneo en la guerra de Bosnia, "un episodio sangriento más de un choque de civilizaciones en curso", ${ }^{39}$ que fue el preludio a la posterior guerra global contra el terrorismo. Así, el supuesto histórico español podría reinterpretarse en forma paralela al conflicto sirio por la inexistencia de consenso internacional respecto del intervencionismo y apoyo a la mezcla de bandos enfrentados, unido a la fanatización de los combatientes, creando una situación compleja que imposibilita la construcción de un tribunal internacional que enjuicie los delitos cometidos en esta guerra, ante la confluencia de intereses contrapuestos entre las distintas potencias involucradas.

\section{LA GUERRA GIVIL SIRIA Y LOS COMBATIENTES EXTRANJEROS: NUEVO SUPUESTO HISTÓRICO DE FUERZA CERO}

La colonización fue vista como la derrota del islam frente al cristianismo, lo que sirvió para la radicalización política y religiosa de la población musulmana a través de teorías islamistas en las que se recuperó el concepto de yihad como

${ }^{38}$ Raúl Carnevali Rodríguez, ibid., p. 188.

${ }^{39}$ Samuel P. Huntington, El choque de civilizaciones, Ciudad de México, Paidós, 2019, p. 348. 
justificación de la lucha contra la ocupación. ${ }^{40}$ El final de la Segunda Guerra Mundial originó la aparición de movimientos de liberación nacional en los territorios coloniales, comenzando la progresiva independencia de estos países, como Jordania (1946), Siria (1946), Israel (1948), Marruecos (1956), Túnez (1958) o Argelia (1962), en algunos casos tras años de guerra y actos de terrorismo, o a través de movilizaciones laicas y religiosas. El partido Baath, surgido a mediados de la década de 1940, es un ejemplo de estos levantamientos, que abogó en su origen por la unidad árabe y el socialismo, ${ }^{41}$ logrando gobernar Siria durante más de 40 años, primero a través de Hafez Al Assad y, desde el año 2000, con su hijo Bashar Al Assad, en un sistema que ha sido calificado por algunos autores como "república hereditaria". 42

Los terroristas islamistas, si bien se consideran herederos de la yihad medieval, están inspirados en las ideologías revolucionarias del siglo XIX, ${ }^{43}$ a nuestro entender, principalmente en las estrategias guerrilleras desarrolladas en el siglo $\mathrm{xx}$, como las doctrinas leninistas, maoístas y guevaristas, por la asimetría de fuerzas enfrentadas. El ideario de la guerra santa en el mundo islámico surgió de la interpretación de algunas aleyas coránicas y algunos ahadit (dichos) del Profeta ${ }^{44}$ causa por la cual Fuente Cobo considera "fácil preconizar un sistema totalitario y teocrático, por las interpretaciones más bárbaras de la Charía" que lleva a "la deshumanización de todos aquellos considerados fuera de la ley islámica”, lo que

${ }^{40}$ Ignacio Fuente Cobo, "El yihadismo en su contexto histórico", en Ministerio de Defensa de España, La internacional yihadista, Madrid, Ministerio de Defensa de España, 2015, p. 49.

${ }^{41}$ Norberto Raúl Méndez, "Sobre la construcción y deconstrucción de Iraq", Convergencia. Revista de Ciencias Sociales, 2005, p. 167.

42 Francisco Berenguer Hernández, "Las posibles consecuencias de la revuelta popular en Siria (DIEEEI11-2011)", Instituto Español de Estudios Estratégicos, 31 de marzo de 2011, http://www.ieee.es/Galerias/fichero/ docs_informativos/2011/DIEEEI11-2011RevueltaPopularSiria.pdf

${ }^{43}$ Jean Flori, Yihad, cruzada: violencia y religión en el cristianismo y el islam, España, Universidad de Granada, 2004, p. 5.

${ }^{44}$ Ibid., p. 73. 
serviría para explicar las atrocidades cometidas por sus partidarios. ${ }^{45}$ Estos crímenes los ha sufrido Occidente en primera persona, al haberse convertido en un objetivo de estos ataques, como el 11-S, el 11-M o el 7-J, el asesinato de los miembros de la revista satírica francesa Charlie Hebdo o los ataques de los denominados lobos solitarios, mediante el apuñalamiento de miembros de fuerzas y cuerpos de seguridad del Estado o en atropellamientos múltiples de población civil.

Hoy, para comprender el yihadismo, hay que atender el contexto histórico, político, religioso y social del islam, por no tratarse de un fenómeno contemporáneo, dado que la yihad es "una guerra de legítima defensa" entendida "como una obligación de todo buen musulmán”, “[...] cuyo objetivo final sería la implantación con carácter universal de la ley islámica, la Charía, dentro de un Califato ideal que reprodujera el existente en los primeros tiempos del islam". ${ }^{46}$ Esta última idea, procedente de la doctrina suní conocida como hanbalismo (proveniente del Hanbalí, una de las cuatro grandes escuelas del pensamiento de esta rama del islam, aparecida entre los siglos Ix y x, y considerada la más rigorista) sienta las bases del islamismo moderno, desarrollando un discurso político que propone la creación de un modelo de sociedad perfecta regida por la ley divina. ${ }^{47}$

El origen de la comunidad árabe (la umma), bajo Mahoma, se fundaba en el islam como factor religioso de cohesión ideológica y en un Estado, todavía embrionario, constituyendo un medio de consolidación de la "paz árabe", frente al estado previo de anarquía y de continua lucha entre clanes rivales. ${ }^{48}$ Tras la muerte de Mahoma, en el siglo viI de nuestra era, como consecuencia de que el profeta no dejó dispuesta su sucesión espiritual y política, el islam se dividió

${ }^{45}$ Ignacio Fuente Cobo, "El yihadismo...", art. cit., p. 39.

46 Loc. cit.

47 Ignacio Fuente Cobo, “Aproximación histórica al fenómeno del yihadismo", Instituto Español de Estudios Estratégicos, 13 de mayo de 2015, pp. 5-6.

${ }^{48}$ Jean Flori, op. cit. 
principalmente en dos grandes grupos: los chiíes, cuya traducción significa "facción" (por ser en principio una minoría) partidarios de considerar sucesor a quien fuese descendiente directo de Mahoma (en origen su primo Alí); y los sunníes, defensores de que el heredero fuese aquel elegido por la comunidad, ${ }^{49}$ que representan el $85 \%$ del total de los 1200 millones de musulmanes que hay en la actualidad, frente al $10 \%$ que suponen los chiíes. ${ }^{50}$

La división existente en el islam es de necesaria observación para comprender lo ocurrido en el conflicto de Siria, al ser este un país de mayoría sunní, con alrededor de $74 \%$ de su población, mientras que $13 \%$ son musulmanes de otras ramas minoritarias como la alawi, ismaelies y chiíes, ${ }^{51}$ y en su contexto transnacional, teniendo en cuenta la situación de Iraq, donde entre 64 y $69 \%$ de su población es chiíe, representando los sunníes entre 29 y $34 \% .52$

Los grupos terroristas islámicos se definen por el carácter internacional de sus ofensivas, de entre los que destacan dos organizaciones, de acuerdo con la parte del islam a la que están afiliadas: Hezbollah, de procedencia chiíe (creado en la década de 1980, en el contexto de la guerra de Israel contra Líbano, donde miembros de la Guardia Revolucionaria de Irán comenzaron a formar y entrenar milicias en Líbano) ha intervenido en el conflicto sirio en apoyo del presidente Al Assad (además de haber sido posiblemente el primer grupo terrorista que ha empleado

${ }^{49}$ Ricardo González, "Suníes y chiíes, un conflicto por el poder vestido de cisma religioso", El País, 3 de enero de 2016, https://elpais.com/ internacional/2016/01/03/actualidad/1451843662_491050.html

${ }^{50}$ Antonio Alonso, "Las dos principales ramas del islam", El País, 10 de abrilde 2015, https:/ / elpais.com/elpais/2015/04/10/media/1428701979 _716224.html

${ }^{51}$ Central Intelligence Agency (CIA), "Syria-The cia World Factbook", CIA, 19 de noviembre de 2018, https://www.cia.gov/the-world-factbook/co untries/syria/

${ }^{52}$ Central Intelligence Agency (CIA), "Iraq-CIA World Factbook", cIA, 19 de noviembre de 2018, https://www.cia.gov/the-world-factbook/cou ntries/iraq/ 
drones para perpetrar ataques) $;{ }^{53}$ y Al-Qaeda, de origen sunii, que podría considerarse como una red terrorista global en la cual pueden distinguirse diferentes facciones regionales, que operan como franquicias de la matriz central: Al Qaeda Península Arábiga o Al Qaeda Magreb Islámico; grupos asociados como Boko Haram, que actúan en Nigeria y, por último, individuos que ejercen de forma independiente, inspirados por la organización. ${ }^{54}$

La novedad que aportó el conflicto sirio, comparando la trayectoria histórica de estos movimientos terroristas, la encontramos en el EI, que aglutina los elementos clave que necesita todo proto-Estado o revolución: la ideología o elaboración teórica; el caudillo o representante de la expansión política y territorial, y el bardo, identificado en el afianzamiento del corpus doctrinal por medio de su difusión y la captación de nuevos partidarios. ${ }^{55}$ Dicha organización plasmó la idea de $\mathrm{Al}$ Zarqawi, encargado de la proyección del salafismo en Iraq, que dio lugar a una transición desde el grupo Al Qaeda al modelo de Califato de Abu Bakr al-Baghdadi, quien a partir de 2012, con la intención de ganar adeptos a su causa, se nutrió de desempleados, extremistas y antiguos presidiarios. Y, a diferencia de otros grupos, además de las ideas fanatizadas, esta organización se ha caracterizado por haber tenido el control efectivo sobre un territorio, desarrollando actividades típicas de un Estado, como la recauda-

53 José María Blanco Navarro, "Hezzbolah, el partido de Dios", Instituto Español de Estudios Estratégicos, 4 de marzo de 2015, pp. 3-6.

54 Óscar Pérez Ventura, "25 años de Al Qaeda: presente y fin de la red terrorista”, en Leandro Martínez Peñas, Amenazas y orden público: efectos y respuestas, de los Reyes Católicos al Afganistán contemporáneo, Madrid, Asociación Veritas para el Estudio de la Historia, el Derecho y las instituciones, 2013, pp. 227-228.

55 Olga Torres Díaz, "La propaganda del DAESH también es cosa de mujeres. De Umm Sumayyah Al-Muhajirah En Dabiq al manifiesto de la brigada Al-Khansaa en internet”, Instituto Español de Estudios Estratégicos, 9 de noviembre de 2015, p. 4 . 
ción de impuestos, labores administrativas, comunicaciones e impartición de justicia. ${ }^{56}$

El terrorismo, empleado como una táctica asimétrica, ha experimentado un crecimiento tanto a nivel de los conflictos armados regionales de Afganistán e Iraq, como a escala planetaria. ${ }^{57}$ Para ello, tomemos como ejemplo Iraq y Siria, donde de acuerdo con la información contenida en el "Global Terrorism Database" de la Universidad de Maryland, ${ }^{58}$ entre 2008 y 2017, se cometieron 12888 ataques terroristas con víctimas mortales (de los cuales, 80 tuvieron más de 50 víctimas), mientras que de 597 agresiones no se conocen cifras.

Desde 2011, año en el que se produjo un auge del yihadismo, como consecuencia de las conocidas primaveras árabes, que provocaron el fin de los regímenes de Egipto, Libia, Túnez y Yemen, ${ }^{59}$ Siria ha soportado una guerra civil que había ocasionado, hasta julio de 2021, un total de 5621954 refugiados oficialmente registrados, de los cuales más de 3 millones estaban en Turquía, ${ }^{60}$ y alrededor de 12 millones de desplazados, de una población de 23 millones de personas que tenía originalmente el país, ${ }^{61}$ con más de 500000 muertos. ${ }^{62}$ Y si

56 Jacobo Morillo Llovo, "Isis: la última evolución del terrorismo", Instituto Español de Estudios Estratégicos, 18 de noviembre de 2016, http://www.ieee.es/Galerias/fichero/docs_opinion/2016/DIEEEO1162016_ISIS_EvolucionTerrorismo_JacoboMorillo.pdf

${ }^{57}$ Federico Aznar Fernández-Montesinos, "Repensando el terrorismo", Instituto Español de Estudios Estratégicos, 15 de agosto de 2018, p. 3.

${ }^{58}$ Global Terrorism Database, (página de internet) https://www.start. umd.edu/gtd $/$ search $/$ ?back $=1 \&$ casualties_type $=$ b\&casualties_max $=$ \&start_yearonly=2008\&end_yearonly=2017\&criterion $1=$ yes\&criterion $2=$ ye s\&criterion $3=$ yes\&dtp2 $=$ some\&success=no\&country $=95,200 \&$ region $=10$

${ }^{59}$ Ignacio Fuente Cobo, “Aproximación histórica...”, art. cit., p. 15.

${ }^{60}$ United Nations High Commissioner for Refugees, UNHCR, "Operational Portal Refugee Situations", unHCR, 7 de julio de 2021, https:// data2.unhcr.org/en/situations/syria

${ }^{61}$ Jesús A. Núñez Villaverde, "La guerra de Siria se acerca al final", Estudios de política exterior, 25 de abril de 2018, https://www.politicaexterior.com/actualidad/la-guerra-de-siria-se-acerca-al-final/

62 "Syrian Observatory says war has killed more than half a million", Reuters, 2 de marzo de 2018, https://www.reuters.com/article/us-mideast- 
bien, como lo expresaba Núñez Villaverde, aún sin haber finalizado la guerra, ésta ya la había ganado Al Assad, pronosticando con ello una continuación de la violencia. ${ }^{63}$

Dicha posición es entendible, al comprender la represión de posguerra que acompaña a cualquier enfrentamiento civil y a la ausencia de mecanismos eficaces para determinar la intervención de los sujetos en el conflicto, unido a la imposibilidad de lograr una transición en la que existan instrumentos destinados a dotar de garantías judiciales a estos detenidos, por la disparidad de intereses de las distintas potencias que se han enfrentado. En el caso de Iraq, donde las autoridades detuvieron a unas 19000 personas ligadas al EI (de las cuales unas 3000 fueron condenadas a muerte), el encarcelamiento en masa y la velocidad con que se dictaron los veredictos de culpabilidad, se generó preocupación internacional ante la posible comisión de errores judiciales ${ }^{64}$ en unos juicios en los que, si no se llegaba a demostrar la inocencia del acusado, procediéndose a su absolución, se arriesgaba a que fuera condenado a 15 años de cárcel, cadena perpetua o muerte en la horca. ${ }^{65}$

En la guerra siria se contabilizaron aproximadamente 1000 grupos armados activos, ${ }^{66}$ distinguiéndose entre el bando de las tropas gubernamentales de Bashar Al Assad (apoyadas internacionalmente por Irán, Rusia y Turquía), enfrentadas a grupos rebeldes contrarios al gobierno, sunníes y nacionalistas kurdos (apoyados por EE.UU. y Arabia Saudí) y al

crisis-syria/syrian-observatory-says-war-has-killed-more-than-half-a-millionidUSKCN1GO13M

63 Jesús A. Núñez Villaverde, op. cit.

64 Qassim Abdul-Zahra y Susannah George, "Iraq holding more than 19,000 because of Is, militant ties", Associated Press, 22 de marzo de 2018, https:/ /apnews.com/aeece6571de54f5dba3543d91deed381

65 Maya Alleruzzo y Salar Salim, "Iraq's Is trials bring swift verdicts, almost all guilty", Associated Press, 19 de abril de 2018, https:/ / www.apnews. com/25a655d5b3cb47c5a0251f596855c98f

${ }^{66}$ Cesáreo Gutiérrez Espada, "El conflicto en Siria (2011-2014) a la luz del derecho internacional y de la geopolítica", Revista UNISCI, 2015, p. 101. 
EI, junto con otros grupos yihadistas, ${ }^{67}$ muestra de la complejidad del conflicto y de la dificultad en la creación de un Tribunal internacional que evite actuaciones arbitrarias.

El fracaso de la Corte Penal Internacional ante el RESURGIR DE LA HISTORIA

En pleno colapso soviético, al escribir en 1989 “¿El fin de la historia?”, Fukuyama acertó haciéndose eco de las opiniones del analista político estadounidense Charles Krauthammer, quien afirmaba que, ante el abandono del marxismo leninismo por la URSS, Rusia volvería a retornar sus ambiciones imperiales del siglo XIx, ${ }^{68}$ al reducirse las opciones de desencadenamiento de una gran guerra entre Estados debido a la "mercantilización común de la política mundial"; aun así, no negaba las posibilidades del aumento de los niveles de "violencia étnica y nacionalista", razones por las cuales deducía "que el terrorismo y las guerras de liberación nacional continuarían siendo un asunto importante en la agenda internacional", ${ }^{69}$ como ha ocurrido en las dos primeras décadas del siglo xxI.

Desde el final de la Segunda Guerra Mundial, enfrentamiento que EE.UU. superó sin apenas daño, como evidencia de que al concluir éste tuviese "el 60 por ciento del producto nacional bruto del mundo" 70 no ha vuelto a haber una gran contienda bélica directa entre las principales potencias (si bien el momento más cercano de producirse fue la crisis de los misiles de Cuba, en 1962). Por el contrario, en la práctica se han sostenido las denominadas guerras proxy, "Una gue-

67 "Quién pelea contra quién en la guerra en Siria”, ввс News, 15 de marzode2016,https://www.bbc.com/mundo/noticias/2015/10/151001_ siria_guerra_quien_rusia_eeuu_az

${ }^{68}$ Francis Fukuyama, op. cit., p. 92.

${ }^{69}$ Francis Fukuyama, op. cit., pp. 99-100.

70 Henry Kissinger, Orden Mundial, México, D.F., Penguin Random House, 2016, p. 281. 
rra entre grupos o países más pequeños, que representan los intereses de otras potencias más grandes, de las que pueden recibir apoyo y ayuda". ${ }^{71}$

A partir de los Tribunales Militares Internacionales de Núremberg y Tokio, se forjó el derecho penal internacional $^{72} \mathrm{y}$, a pesar de la pervivencia de estas actuaciones, no fue sino con el final de la Guerra Fría que volvió a darse un proceso judicial internacional, con la apertura de sesiones del Tribunal Penal Internacional para la Antigua Yugoslavia el 9 de noviembre de $1994 .{ }^{73}$ Ya en la década de 1950, desde Naciones Unidas se había trabajado un borrador de estatuto para un Tribunal Penal Internacional, sin que prosperase la iniciativa por la situación de bipolarización existente, pero no sería hasta 1989, a propuesta de Trinidad y Tobago, que se retomarían estos estudios ${ }^{74}$ que permitieron la convocatoria de la Asamblea General de Naciones Unidas a una conferencia diplomática en Roma, entre el 15 de junio y el 17 de julio de 1998. De estas sesiones se obtuvo el Estatuto de la Corte Penal Internacional, también conocido como Estatuto de Roma, que entró en vigor el 1 de julio de 2002,75 el cual se convirtió en "el primer tribunal penal internacional permanente, creado por un tratado y con vocación universal". ${ }^{76}$

En 1998, el establecimiento de la Corte Penal Internacional respondía a la necesidad de dotar al orden jurídico internacional del medio con qué castigar delitos de especial

71 "Proxy Wars", Cambridge Dictionary, Cambridge University Press, 2020, https://dictionary.cambridge.org/es/diccionario/ingles/proxy-war

72 Fernando Pignatelli y Meca, "La punición de las infracciones del Derecho Internacional Humanitario. Los tribunales internacionales de crímenes de guerra", en José Luis Rodríguez-Villasante y Prieto y Joaquín López Sánchez, Derecho Internacional Humanitario, Valencia, Tirant Lo Blanch, 2017, p. 1031.

${ }^{73}$ Ibid., p. 1070.

${ }^{74}$ Ibid., p. 1091.

Loc. cit.

${ }^{75}$ Alfredo Liñán Lafuente, op. cit., p. 78.

${ }^{76}$ Elena Maculan, "La Corte Penal Internacional", en Alicia Gil y Elena Maculan, Derecho Penal Internacional, Madrid, Dykinson, 2019, p. 83. 
gravedad contra la humanidad, ${ }^{77}$ constituido actualmente por 123 Estados parte, ${ }^{78}$ entre los que no se encuentran algunos de los países más poblados del mundo, como la India, Pakistán, Indonesia o China, que es (este último) también miembro permanente del Consejo de Seguridad de Naciones Unidas (CSNU), órgano del cual sólo Francia y el Reino Unido forman parte de la CPI, debido a que si bien EE.UU. y Rusia son países firmantes, al no haber ratificado el instrumento, no están obligados a acatar las decisiones del tribunal. La pertenencia al cSNU es un hecho relevante, porque es el órgano principal de la onu destinado a mantener la paz y seguridad internacional, así como por el poder de veto de sus miembros permanentes sobre asuntos que trata.

Asimismo, la importancia de pertenecer al cSNU reside en la facultad de este órgano de remitir a la cPI cualquier hecho que pueda parecer constitutivo del crimen de genocidio, lesa humanidad, guerra y agresión, de acuerdo con el artículo 13b de su Estatuto, sin omitir que, para lograr esa remisión, ningún miembro deberá ejercer su derecho de veto. Esta facultad fue ejercida masivamente por la URSS entre 1955 y 1985, al presentar 116 vetos, frente a los 39 de EE.UU., 22 del Reino Unido, 15 de Francia, y 4 de China; ${ }^{79}$ al haberse mantenido el ejercicio de esta capacidad, como se confirmó en 2014 con motivo de la guerra civil siria, cuando China y Rusia fueron los únicos Estados del cSNU que vetaron la propuesta de Francia de someter la situación del conflicto a la CPI. ${ }^{80}$

77 Pignatelli y Meca, “La punición...”, art. cit. p. 1031. Ibid., p. 1030.

78 The States Parties to the Rome Statute, International Criminal Court, 2020, https://asp.icc-cpi.int/en_menus/asp/states\%20parties/ pages $/$ the $\% 20$ states $\% 20$ parties $\% 20$ to $\% 20$ the $\% 20$ rome $\% 20$ statute.aspx

${ }^{79}$ José A. Pastor Ridruejo, Curso de Derecho Internacional Público y organizaciones internacionales, Madrid, Tecnos, 2016, p. 763.

${ }^{80}$ United Nations, "Referral of Syria to International Criminal Court Fails as Negative Votes Prevent Security Council from Adopting Draft Resolution”, United Nations, 2014, https:/ /www.un.org/press/en/2014/sc11407. doc.htm 
$\mathrm{Al}$ momento de creación de la CPI, el otrora poderoso bloque soviético era un espectro encarnado en sus 17 Estados herederos, de entre los cuales, la República de la Federación Rusa había asumido la posición de miembro permanente del Consejo de Seguridad de Naciones Unidas, tras el Acuerdo de Alma Ata, del 21 de diciembre de 1991, ${ }^{81}$ mientras afrontaba las guerras de Chechenia, que causó aproximadamente 100000 muertos, y una debacle económica que hizo que, en 1996, aproximadamente 37 millones de rusos, el $25 \%$ de su población, viviese en situación de pobreza. ${ }^{82}$ Ello impidió al país desplegar una política exterior estable, como aconteció en la guerra de los Balcanes, donde dieron un limitado apoyo a Serbia (cristianos ortodoxos) sin lograr igualar el respaldo occidental a las fuerzas croatas (de religión católica), pese a las constantes denuncias de Rusia por los bombardeos de la Organización del Tratado del Atlántico Norte (OTAN) contra serbios y bosnios, que llegaron a calificar públicamente de genocidio, ${ }^{83}$ lo cual generó la incapacidad, denominada "síndrome de Kosovo", que define el sentimiento percibido por Rusia tras la desintegración de la URss, y su falta en la toma de decisiones internacionales, como la ampliación oriental de la OTAN o la declaración de independencia de Kosovo. ${ }^{84}$

Como lo expresa Kissinger "la tradición occidental exige el apoyo a las instituciones democráticas y las elecciones libres". ${ }^{85}$ Esta máxima podría responder al por qué de la ratificación de Francia y Reino Unido de la CPI, pero no explica la ausencia de EE.uU., con su fuerte vinculación a la difusión de los valores ideológicos de la democracia y los derechos humanos (DDHH). A continuación, recogemos nuevamente las opiniones de Kissinger:

${ }^{81}$ José A. Pastor Ridruejo, op. cit., p. 762.

82 Naomi Klein, La doctrina del shock, Ciudad de México, Paidós, 2014, p. 319 .

83 Samuel P. Huntington, op. cit., pp. 338-341.

${ }^{84}$ Francisco Berenguer Hernández, op. cit., p. 117.

${ }^{85}$ Henry Kissinger, op. cit., p. 133. 
Descuidar el presente ignorando que el elemento de seguridad conlleva el riesgo de una catástrofe inmediata [...] Pueden ocurrir acontecimientos cuyas consecuencias, como el genocidio, son tan horrendas que inclinan la balanza hacia la intervención sin consideraciones estratégicas. Pero, por regla general, la vía más sustentable implicará una mezcla de realismo e idealismo, a menudo tomados como opuestos incompatibles en el debate norteamericano. ${ }^{86}$

La no ratificación de EE.uU. de la CPI (lo mismo que Rusia) se debe a una razón pragmática, ante la posible incompatibilidad entre la defensa de la justicia internacional, contra las limitaciones que pudiese ésta generar en las estrategias de protección de sus intereses estatales. El único hecho por el que EE.UU. enjuició a miembros de su personal militar en un escenario bélico, en el trascurso de la Guerra Fría (acción que no fue repetida por ningún país durante este periodo), fue con motivo de la masacre de My-Lai, perpetrada durante la guerra de Vietnam, como violación del derecho penal estadounidense. ${ }^{87}$

Por otra parte, la no pertenencia de China a la CPI puede interpretarse si se entiende que este país es heredero de la tradición soviética, contrario a la defensa y difusión de los DD.HH. Para los Estados de la extinta URss, a través del empleo del materialismo propio del marxismo como eje vertebrador de sus sociedades, se concebía al ser humano definido por el sistema de producción imperante en cada etapa histórica, que determinaba la existencia del derecho vigente, como una imposición de la clase dirigente, en tanto que no provenga de la victoria del proletariado; esto llevaba consigo el rechazo a los DD.HH. por considerarlos un elemento abstracto e idealista, que no permite la liberación de la humanidad de la explotación, no por la formulación de principios, sino exclusivamente a través de la creación de condiciones

${ }^{86}$ Loc. cit.

${ }^{87}$ Fernando Pignatelli y Meca, “La punición...”, art. cit., p. 1046. 
alcanzadas en los países socialistas. ${ }^{88}$ Con esta argumentación, podría comprenderse por qué China se abstiene de obligarse por el CPI, permitiéndole desarrollar políticas contrarias a los DDHH, cuya acción más visible es la sostenida contra la etnia uigur. El país mantiene una política de exclusión contra este grupo, en la provincia de Xinjiang, que habría llevado a la detención en campos de concentración a 3 millones de personas, de los 10 que integran su población, ${ }^{89}$ hecho que ha ocasionado que la Alta Comisionada del Consejo de Derechos Humanos de Naciones Unidas haya expresado su intención de "analizar en profundidad la situación de los DDHH en China, incluyendo la situación de los miembros de la minoría uigur". 90

En el presente, sigue existiendo un compromiso internacional en el marco de la Asamblea General de Naciones Unidas; muestra de ello es la Declaración de la reunión de alto nivel de la Asamblea General sobre el Estado de derecho en los planos nacional e internacional, contenida en la Resolución aprobada por la Asamblea General el 24 de septiembre de $2012,{ }^{91}$ que recogía el compromiso de los Estados miembros en el párrafo 22:

${ }^{88}$ Juan Maestre Alfonso, "La posición de los países socialistas frente a los derechos humanos", Revista de estudios políticos, 1981, pp. 138-140.

89 Phil Stewart, "China putting minority Muslims in "concentration camps, U.s. says", Reuters, 4 de mayo de 2019, https:/ /www.reuters.com/ article/us-usa-china-concentrationcamps/china-putting-minority-mus lims-in-concentration-camps-us-says-idUSKCN1S925K

${ }^{90}$ United Nations High Commissioner for Human Rights (UNHCHR), "High Commissioner updates the Human Rights Council on human rights concerns, and progress, across the world", UNHCHR, 27 de febrero de 2020, https://www.ohchr.org/EN/NewsEvents / Pages/DisplayNews. aspx?NewsID $=25621 \&$ LangID $=\mathrm{E}$

91 Naciones Unidas, Asamblea General, Declaración de la reunión de alto nivel de la Asamblea General sobre el estado de derecho en los planos nacional e internacional, 30 de noviembre de 2012, A/ RES/67/1, https://undocs.org/es/A/RES/67/1 
[...] a asegurar que no se tolere la impunidad por el genocidio, los crímenes de guerra y los crímenes de lesa humanidad, ni por las violaciones del derecho internacional humanitario y las violaciones graves de las normas de derechos humanos, y que tales violaciones se investiguen debidamente y reciban las sanciones apropiadas, lo que incluye hacer comparecer ante la justicia a los autores de cualquier delito, mediante mecanismos nacionales o, cuando proceda, mecanismos regionales o internacionales, de conformidad con el derecho internacional, y, con ese fin, alentamos a los Estados a que fortalezcan los sistemas e instituciones judiciales nacionales.

Otro hecho clave en el compromiso sostenido por la Asamblea General en defensa del derecho internacional humanitario y de los derechos humanos, fue la adopción en 2016 de la Resolución 71/248, ${ }^{92}$ que estableció el Mecanismo Internacional, Imparcial e Independiente para Ayudar en la Investigación y el Enjuiciamiento de los Responsables de los Delitos Más Graves en virtud del Derecho Internacional Cometidos en la República Árabe Siria desde marzo de 2011.

A pesar de la postura defendida por la Asamblea General, máximo elemento garante de la pluralidad de la onU, no puede hacerse a un lado que el foro de verdadera toma de decisiones políticas de la onu es el CSNU, órgano que no ha adoptado ningún mecanismo destinado a este objetivo, como se comprueba prestando atención a las distintas resoluciones aprobadas en relación a la guerra civil siria. Sirva de ejemplo la s/Res/2254(2015), ${ }^{93}$ en la que se reconocía que "solamente se alcanzará una solución sostenible a la crisis actual en Siria mediante un proceso político inclusivo y dirigido por

92 Naciones Unidas, Asamblea General, Mecanismo Internacional, Imparcial e Independiente para Ayudar en la Investigación y el Enjuiciamiento de los Responsables de los Delitos de Derecho Internacional Más Graves Cometidos en la República Árabe Siria desde marzo de 2011, 21 de diciembre de 2016, https://undocs.org/es/A/RES/71/248

${ }^{93}$ Naciones Unidas, Consejo de Seguridad, Resolución 2254 (2015), 18 de diciembre de 2015, https://undocs.org/sp/S/RES/2254\%20(2015) 
Siria que colme las aspiraciones legítimas del pueblo sirio [...]", expresando "su apoyo a este respecto a un proceso político dirigido por Siria y facilitado por las Naciones Unidas, que en un plazo de seis meses establezca una gobernanza creíble, incluyente y no sectaria, y un calendario y un proceso para la redacción de una nueva constitución, y [...] la celebración de elecciones libres y justas"; o la más reciente $\mathrm{s}$ / RES/2504(2020), ${ }^{94}$ que continúa la defensa de las metas recogidas en la s/REs/2254(2015) e indicaba que "más de 11.1 millones de personas necesitan asistencia humanitaria en Siria", además de recordar "que algunas de las violaciones y los abusos cometidos en Siria pueden constituir crímenes de guerra y crímenes de lesa humanidad", sin que en ningún caso concibiese una propuesta de mecanismo efectivo para investigar y enjuiciar tales delitos.

\section{REFLEXIONES FINALES}

La división mundial durante la guerra civil española, materializada en el fracaso de la Sociedad de Naciones, como pudo comprobarse con el posterior estallido de la Segunda Guerra Mundial, impidió la propuesta y creación de cualquier tribunal de justicia internacional encargado de enjuiciar con garantías a los combatientes del conflicto español. No sería hasta 1945 que se concibieron tribunales para juzgar los crímenes de la recién acabada contienda, gracias al consenso de las potencias victoriosas, sin que se crearan nuevas formas en el curso del enfrentamiento de la Guerra Fría. Habría que esperar nuevamente al status quo surgido en la década de 1990 para la aparición de tribunales herederos de la labor de Núremberg y Tokio, en forma de órganos judiciales ad hoc y mixtos, hasta alcanzar la cúspide con la creación de la CPI.

94 Naciones Unidas, Consejo de Seguridad, Resolución 2504 (2020), 10 de enero de 2020, https://undocs.org/es/S/RES/2504(2020) 
Un proceso de consolidación frustrado por la falta de compromiso de las principales potencias a someterse a la CPI, que denota la existencia de una doble moral, en tanto que se promueven medidas tendentes a lograr la seguridad mundial, sin que queden constreñidas por éstas los intereses de tales Estados. Por esta razón se impide el ejercicio efectivo y la consolidación del derecho penal internacional, lo que muestra la inviabilidad para construir un órgano destinado al enjuiciamiento de los crímenes que se hayan podido cometer durante la guerra civil siria (tanto por tropas gubernamentales, como por los distintos grupos paramilitares, rebeldes, y miembros del EI) debido a la falta de unión internacional entre los Estados con mayor poder geopolítico.

\section{Bibliografía}

Abdul-Zahra, Q. y S. George, "Iraq holding more than 19,000 because of Is, militant ties”, Associated Press, 22 de marzo de 2018, https:/ /apnews.com/aeece6571de54f5dba3543d91deed 381

Abraham Lincoln Brigade Archives, "Jewish Volunteers in the Spanish Civil War", Abraham Lincoln Brigade, 21 de noviembre de 2008, http://www.alba-valb.org/resources/lessons/jewishvolunteers-in-the-spanish-civil-war/jewish-volunteers-in-thespanish-civil-war

Alleruzzo, M. y S. SAlim, "Iraq's IS trials bring swift verdicts, almost all guilty", Associated Press, 19 de abril de 2018, https:/ / www.apnews.com/25a655d5b3cb47c5a0251f596855c98f

Alonso, A., "Las dos principales ramas del islam", El País, 10 de abril de 2015, https:/ /elpais.com/elpais/2015/04/10/media/ 1428701979_716224.html

Andrés-Gallego, J. y A. Pazos, Archivo Gomá: documentos de la guerra civil, Madrid, Consejo Superior de Investigaciones Científicas, 2001.

Aróstegui, J., La guerra civil, Madrid, Grupo 16, 1985.

Aznar Fernández-Montesino, F., "La finalización de los conflictos", Instituto Español de Estudios Estratégicos, 22 de agosto 
de 2018, http://www.ieee.es/Galerias/fichero/docs_analisis/ 2018/DIEEEA32-2018_Finalizacion_Conflictos_FAFM.pdf Aznar Fernández-Montesinos, F., "Repensando el terrorismo", Instituto Español de Estudios Estratégicos, 15 de agosto de 2018, http://www.ieee.es/Galerias/fichero/docs_analisis/2018/ DIEEEA31-2018_Repensando_Terrorismo_FAFM.pdf

Berenguer Hernández, F., "Las posibles consecuencias de la revuelta popular en Siria (DIEEEI1 1-2011)", Instituto Español de Estudios Estratégicos, 31 de marzo de 2011, http:/ /www.ieee.es/ Galerias/fichero/docs_informativos/2011/DIEEEI112011RevueltaPopularSiria.pdf

Blanco Navarro, J., "Hezbollah, el partido de Dios", Insituto Espanol de Estudios Estratégicos, 4 de marzo de 2015, http://www. ieee.es/Galerias/fichero/docs_investig/2015/DIEEEINV012015_Hezbollahx_El_partido_de_Dios_JMBlanco.pf

Bremmer, I. y N. Roubini, "A G-Zero World”, Foreign Affairs, 2011, https:/ / www.foreignaffairs.com/articles/2011-01-31/g-zeroworld

CARDOnA, G., "El Ejército popular y las Brigadas Internacionales. ¿Cuál fue la importancia de las brigadas?”, en M. Requena Gallego y R. Sepúlveda Losa, Las brigadas internacionales: el contexto internacional, los medios de propaganda, literatura y memorias, Cuenca, Ediciones de la Universidad de Castilla-La Mancha, 2003, pp. 37-52.

Carnevali Rodríguez, Raúl, "Los principios de primacía y complementariedad. Una necesaria conciliación entre las competencias de los órganos penales nacionales y los internacionales", Revista de Derecho de la Universidad Austral de Chile, 2010, pp. 181-200.

Carrubba, M., "La memoria del Cuerpo de Tropas Voluntarias en las publicaciones del régimen fascista y en las biografías de los voluntarios”, I Encuentro de Jóvenes Investigadores en Historia Contemporánea de la Asociación de Historia Contemporánea : Zaragoza, 26, 27 y 28 de septiembre de 2007, 2008.

Cayuela Fernández, J., "Prefacio”, en J. Cayuela Fernández y R. Gabaldón Pacheco, Los juicios al nazismo. Núremberg: la Segunda 
Guerra Mundial en el espejo de la catástrofe, Cuenca, Ediciones de la Universidad de Castilla-La Mancha, 2018, pp. 11-14.

Central Intelligence Agency (CIA), "Iraq-CIAWorld Factbook", Central Intelligence Agency, 19 de noviembre de 2018, https://www. cia.gov/library/publications/the-world-factbook/geos/iz.html Central Intelligence Agency (CIA), "Syria-The cIA World Factbook", Central Intelligence Agency, 19 de noviembre de 2018, https:// www.cia.gov/library/publications/the-world-factbook/geos/ sy.html

DAwoD, H., "El Estado Islámico está muy adaptado a la guerra moderna”, en É. Fottorino, Qué es ISIS: ensayos para comprender el terrorismo actual, Ciudad de México: Ediciones Culturales Paidós, 2016, pp. 53-62.

De Quesada, A., The Spanish Civil War: 1936-1939 (2) Republican Forces, Gran Bretaña, Osprey Publishing Ltd, 2015.

Diez De Velasco Vallejo, M., Instituciones de Derecho Internacional Público. Madrid, Tecnos, 2013.

Elkin, M., “Opening Franco's Graves", Archaeology, septiembre/ octubre de 2006, https://archive.archaeology.org/0609/abstracts/franco.html

Esteban, J., "Las brigadas internacionales y la guerra civil en la literatura”, en M. Requena Gallego, La guerra civil española y las brigadas internacionales, Cuenca, Editorial de la Universidad de Castilla-La Mancha, 1998, pp. 133-146.

Filiu, J.-P., "Un enfrentamiento apocalíptico", en É. Fottorino, Qué es IIIS: ensayos para comprender el terrorismo actual, Ciudad de México, Ediciones Culturales Paidós, 2016, pp. 153-156.

FLORI, J., Yihad, cruzada: violencia y religión en el cristianismo y el islam, España, Universidad de Granada, 2004.

FotTorino, É., “Introducción”, en É. Fottorino, Qué es isIs: ensayos para comprender el terrorismo actual (págs. 7-10), Ciudad de México, Ediciones Culturales Paidós, 2016, pp. 7-10.

Foucher, M., "Una ambición territorial”, en É. Fottorino, Qué es ISIS: ensayos para comprender el terrorismo actual, Ciudad de México, Ediciones Culturales Paidós, 2016, pp. 42-52.

Freeden, M., Ideology: a very short introduction, Oxford, University Press, 2003. 
Fuente Сово, I., "El yihadismo en su contexto histórico", en M. d. España, La internacional yihadista, Madrid, Ministerior de Defensa de España, 2015a, pp. 37-70.

Fuente Сово, I., "Aproximación histórica al fenómeno del yihadismo", Instituto Español de Estudios Estratégicos, 13 de mayo de 2015b, http://www.ieee.es/Galerias/fichero/docs_analisis/20 15/DIEEEA28-2015_Evolucion_Yihadismo_IFC.pdf

Fukuyama, F., ¿El fin de la Historia? y otros ensayos, Madrid, Alianza Editorial, 2019.

GonzÁlez, R., "Suníes y chiíes, un conflicto por el poder vestido de cisma religioso", El País, 3 de enero de 2016, https:/ / elpais. com/internacional/2016/01/03/actualidad/1451843662_ 491050.html

Gutiérrez Espada, C., "El conflicto en Siria (2011-2014) a la luz del derecho internacional y de la geopolítica", Revista UNISCI (37), enero de 2015, pp. 99-131, https://www.ucm.es/data/ cont/media/www/pag-72478/UNISCIDP37-5GUTIERREZ.pdf

Новsbawm, E., Guerra y paz en el siglo xхI, Ciudad de México: Ediciones Culturales Paidós, 2019.

Hoffmann, G., "Prisioneros internacionales en los campos de concentración de Franco", Ebre 38: revista internacional de la guerra civil, 1936-1939, 2017, pp. 11-18.

Hudson Teslik, L., "Backgrounder: Iraq, Afghanistan, and the U.s. Economy", The New York Times, 4 de febrero de 2008, https:// archive.nytimes.com/www.nytimes.com/cfr/world/ slot3_20080204.html

Huntington, S., El choque de civilizaciones, Ciudad de México, Ediciones Culturales Paidós, 2019.

Igualada Tolosa, C., "Dáesh: provincias y grupos afiliados", Ejército, LXXIX (930), octubre de 2018, pp. 12-19, https:/ / ejercito.defen sa.gob.es/Galerias/multimedia/revista-ejercito/2018/930// accesible/Revista_Ejercito_Accesible.pdf

The States Parties to the Rome Statute, International Criminal Court, 2020, https:/ /asp.icc-cpi.int/en_menus/asp/states\%20parties/ pages /the $\% 20$ states $\% 20$ parties $\% 20$ to $\% 20$ the $\% 20$ rome $\% 20$ sta tute.aspx 
Kissinger, H., Orden Mundial, México, D.F., Penguin Random House, 2016.

KLeIn, N., La doctrina del shock, Ciudad de México, Paidós, 2014.

Liñán Lafuente, A., "Los tribunales penales híbridos e internacionalizados", en A. Gil y E. Maculan, Derecho penal internacional, Madrid, Dykinson, 2019, pp. 115-144.

Maculan, E., "La Corte Penal Internacional", en A. Gil y E. Maculan, Derecho Penal Internacional, Madrid, Dykinson, 2019, pp. 83-114.

Maestre Alfonso, J., "La posición de los países socialistas frente a los derechos humanos", Revista de estudios políticos (19), 1981, pp. 135-144, https://dialnet.unirioja.es/servlet/articulo?codigo $=26641$

Méndez, N. R., "Sobre la construcción y deconstrucción de Iraq", Convergencia. Revista de Ciencias Sociales, 12 (38), mayo-agosto de 2005, pp. 155-184.

Mesa García, B., "La rebelión tuareg y la sombra de Al Qaeda", Instituto Español de Estudios Estratégicos, 30 de abril de 2012, http:/ / www.ieee.es/Galerias/fichero/docs_opinion/2012/ DIEEEO37-2012_RebelionTuaregSombraAlQaeda_Beatriz Mesa.pdf

Morillo Llovo, J., "Isis: la última evolución del terrorismo”, Instituto Español de Estudios Estratégicos, 18 de noviembre de 2016, http:/ /www.ieee.es/Galerias/fichero/docs_opinion/2016/ DIEEEO116-2016_ISIS_EvolucionTerrorismo_JacoboMori llo.pdf

Neumann, F., Behemoth: pensamiento y acción en el nacional-socialismo, México, Fondo de Cultura Económica, 1983.

Nolte, E., La guerra civil europea, 1917-1945: nacionalsocialismo y bolchevismo, México, Fondo de Cultura Económica, 2001.

Núñez Villaverde, J., "La guerra de Siria se acerca al final", Estudios de política exterior, 25 de abril de 2018, https://www.politi caexterior.com/actualidad/la-guerra-de-siria-se-acerca-al-final/

Oliver Monteso, C., "La Legión Cóndor en Navarra - campo de aviación de Buñuel - 1937-1938", Revista del Centro de Estudios Merindad de Tudela, 2010, pp. 7-13.

Onfray, M., "La escoba del aprendiz de brujo", en É. Fottorino, Qué es ISIS: ensayos para comprender el terrorismo actual (págs. 63- 
70), Ciudad de México, Ediciones Culturales Paidós, 2016, pp. 63-70.

Pastor Ridruejo, J., Curso de Derecho Internacional Público y organizaciones internacionales, Madrid, Tecnos, 2016.

Pérez Ventura, Ó., "25 años de Al Qaeda: presente y fin de la red terrorista”, en L. Martínez Peñas, Amenazas y orden público: efectos y respuestas, de los Reyes Católicos al Afganistán contemporáneo, Madrid, Asociación Veritas para el Estudio de la Historia, el Derecho y las instituciones, 2013, pp. 227-273.

Pignatelli y Meca, F., "La punición de las infracciones del Derecho Internacional Humanitario. Los tribunales internacionales de crímenes de guerra”, en J. Rodríguez-Villasante y Prieto y J. López Sánchez, Derecho Internacional Humanitario, Valencia, Tirant Lo Blanch, 2017a, pp. 1029-1088.

Pignatelli y Meca, F., "La Corte Penal Internacional”, en J. Rodríguez-Villasante y Prieto y J. López Sánchez, Derecho Internacional humanitario, Valencia, Tirant Lo Blanch, 2017b, pp. 1089-1144. Preston, P., El holocausto español, Madrid, Debate, 2011.

"Proxy Wars", Cambridge Dictionary, Cambridge University Press, 2020, https://dictionary.cambridge.org/es/diccionario/ingles /proxy-war

"Quién pelea contra quién en la guerra en Siria”, ввс News, https:/ / www.bbc.com/mundo/noticias/2015/10/151001_siria_guerra _quien_rusia_eeuu_az

Ramírez Sainz, L., "La Legión Cóndor desde varias perspectivas", maGAzin (17), 2006, pp. 44-51.

Requena Gallego, M y R. Sepúlveda Losa, "Prólogo", en M. Requena Gallego y R. M. Sepúlveda Losa, Las brigadas internacionales : el contexto internacional, los medios de propaganda, literatura y memorias, Cuenca, Ediciones de la Universidad de Castilla-La Mancha, 2003, pp. 9-14.

Salas, R., "La división azul", Espacio, Tiempo y Forma (2), 1989, pp. 241-269.

SÁnchez Asiaín, J. A., La financiación de la guerra civil española, Barcelona, Crítica, 2012.

Skoutelsky, R., "El regreso de los voluntarios. La memoria de las Brigadas", en M. Requena Gallego y R. Sepúlveda Losa, Las bri- 
gadas internacionales: el contexto internacional, los medios de propaganda. Literatura y memorias, Cuenca, Ediciones de la Universidad de Castilla-La Mancha, 2003, pp. 143-156.

Stewart, P., "China putting minority Muslims in "concentration camps', u.s. says”, Reuters, 4 de mayo de 2019, https://www.re uters.com/article/us-usa-china-concentrationcamps/chinaputting-minority-muslims-in-concentration-camps-us-saysidUSKCN1S925K

"Syrian Observatory says war has killed more than half a million", Reuters, 2 de marzo de 2018, https://www.reuters.com/article/us-mideast-crisis-syria/syrian-observatory-says-war-has-killed-more-than-half-a-million-idUSKCN1GO13M

Thiollet, H., "El espectro de la invasión de 2003", en É. Fottorino, Qué es ISIS: ensayos para comprender el terrorismo actual, Ciudad de México, Ediciones Culturales Paidós, 2016, pp. 41-44.

Torres Díaz, O., "La propaganda del Daesh también es cosa de mujeres. De Umm Sumayyah Al-Muhajirah En Dabiq al manifiesto de la brigada Al-Khansaa en internet", Instituto Español de Estudios Estratégicos, 9 de noviembre de 2015, http:/ / www.ieee. es/Galerias/fichero/docs_opinion/2015/DIEEEO121-2015_ Propaganda_Daesh_Mujeres_OlgaTorres.pdf

Tuñón De Lara, M., La Segunda República, Madrid, Grupo 16, 1985.

United Nations (UN), "Referral of Syria to International Criminal Court Fails as Negative Votes Prevent Security Council from Adopting Draft Resolution", United Nations, 22 de mayo de 2014, https://www.un.org/press/en/2014/sc11407.doc.htm

United Nations High Commissioner for Human Rights (UNHCHR), "High Commissioner updates the Human Rights Council on human rights concerns, and progress, across the world", UNHCHR, 27 de febrero de 2020, https://www.ohchr.org/EN/NewsEv ents/Pages/DisplayNews.aspx?NewsID=25621\&LangID=E

United Nations High Commissioner for Refugees, UnHCR, "Operational Portal Refugee Situations", UNHCR, 7 de julio de 2021, https://data2.unhcr.org/en/situations/syria

VIÑAs, Á., "La creación de las Brigadas Internacionales", en J. Sánchez Cervelló y S. Agudo Blanco, Las Brigadas Internacionales: 
nuevas perspectivas en la historia de la Guerra Civil y del exilio, Tarragona, Publicaciones URV, 2015, pp. 15-24.

Weber, O., "El feudo del terror", en É. Fottorino, Qué es isIs: ensayos para comprender el terrorismo actual, Ciudad de México, Ediciones Culturales Paidós, 2016, pp. 137-146.

Zaloga, S., Spanish Civil War: the providing ground for Blitzkrieg, Great Britain, Osprey Publishing Ltd., 2010. 